\title{
Performance Management in Counties: A Position Paper On Devolution in Kenya
}

\author{
Dorothy Owuor Jonyo, PhD (TSC -Secretariat) \\ Bonn Odera Jonyo, (Principal Research Officer) \\ Dennis Maoga Manyara, (County Government)
}

Doi: 10.19044/elp.v5no1a2 ～URL:http://dx.doi.org/10.19044/elp.v5no1a2

\begin{abstract}
Purpose - The purpose of this paper is to review existing literature on performance management in counties, a new feature in Kenya that influences organizational performance and to construct a framework that could be valuable for leadership of the devolved units.

Design - This paper used a systematic review of articles on the landscapes that influence performance management. The purpose of this study is to collect and summarize all empirical evidence from literature that forms a perfect fit for this review.

Findings - The findings of the study have been woven together in a proposed framework on performance management leadership competencies that in turn influence organizational performance.

Research limitations/implications - This paper is a literature review on the performance management of counties in Kenya as a new phenomenon following the promulgation of a new constitution in 2010; therefore, structures are yet to take route and be subjected to empirical testing.

Practical implications - Leaders can leverage the results of this study to enhance their leadership competencies for improving the counties' performance on human capital and organizational levels.

Value - There are few studies on the performance management on counties as this is a new phenomenon in Kenya on organizational performance. The County Governments should therefore adopt performance management systems in line with vision 2030 and proper strategies that will make them more efficient and effective to meet the citizens' expectations on devolution and to enable them to achieve competitive advantage and superior economic development performance. This paper has identified key variables that play a significant role in helping counties perform effectively.
\end{abstract}

Keywords: Performance management, counties, promulgation, organization performance, devolution. 


\subsection{Background information}

Governments all over the world pride themselves on the ability to publicize their development track record and engagements at every opportunity. Performance management is a force for both vertical and horizontal integration. Hartle, (1995) postulates that performance management should be integrated into the way business is managed and linked with other key processes such as business strategy, employee development and total quality management. It is strategy that is concerned with the broader issues confronting businesses. Performance management describes a method of enabling people in an organization to perform at their best to accomplish goals and objectives that contribute to the success of that organization.

Performance management is referred to as a strategic and integrated approach to delivering sustained success to organizations by improving the performance of the people who work in them and by developing the capabilities of teams and individual contributions (Armstrong \& Baron, 1998). It therefore embraces both behaviour and outcomes in a systematic process of: planning work and setting expectations; continually monitoring performance; developing the capacity to perform; and periodically rating performance in a summary fashion rewarding good performance. This traditional approach is captured in the definition of performance management systems espoused by Buchner (2007) as a process for establishing a shared understanding about what is to be achieved, and how it is to be achieved, and an approach to managing people that increases the probability of achieving high performance, growth and success.

The genesis of performance management in the Public Service in Kenya is traceable to the Economic Recovery Strategy (ERS) and Wealth and Employment Creation of 2003-2007. At the County Government level, performance management is legally prescribed through various sections of the County Government Act of 2012 (CGA), Public Finance Management Act, 2012 (PFM), and the Mwongozo Code of Governance for State Corporations. Hope (2001) points out that performance contracts specify the mutual performance obligations, intentions and the responsibilities that a government requires public officials or management of public agencies or ministries to meet over a stated period. Therkildsen (2001) speculates that performance contracts if well executed increase political accountability by making it easier for managers to match targets with political priorities. Politicians can, in turn, hold managers accountable for their performance as being witnessed in many developing countries.

The CGA Section 47(1), requires the County Executive Committee to design a performance management plan to evaluate performance of the county public service and the implementation of policies. The plan provides for among others: objective, measurable and time bound performance indicators, 
linkage to mandates, annual performance reports, Citizen Participation in the evaluation of performance of county government and public sharing of performance progress reports. Further, the CGA Section 103 identifies the objectives of county planning that include: ensuring harmony between national, county and sub-county spatial planning requirements whereby each county is required to have planning unit in place which ensures linkage between county plans and the National planning framework as per Section 105 of the CGA.

The PFM Act of 2012 Section 126 (1) also requires every county to prepare a development plan which identifies: strategic priorities for the medium term that reflect the county government's priorities and plans; programs to be delivered with details for each program of; the strategic priorities to which the program will contribute, the service or goods to be provided, measurable indicators of performance where feasible, and the budget allocated to the program.

The underlying objective of a CPMF is to promote accountability in service delivery by ensuring that tasks are performed efficiently, effectively and economically. Also, a performance framework provides a mechanism for citizen to engage and evaluate the performance of their county government. The CPMF is composed of seven (7) components. These components include; Vision 2030, 10-Year County spatial/sector plans, 5-Year County Integrated Development Plan (CIDP), 5-Year departmental strategic plans, Annual Development Plans (ADP), Performance Contracting (PC), Performance Appraisal System (PAS) and Monitoring and Evaluation and Reporting.

Performance Management is often taken to be fundamental to delivery of improved services. Emphasis on performance management for delivery of results is undoubtedly influenced by the basic assumption which lies in its professed ability to unite the attention of institution members on a common objective and galvanize them towards the attainment of this objective (Balogun, 2003). However, in the Counties there are tools such as Performance Contracts (PC), Staff Performance Appraisal Systems (SPAS), Rapid Results Initiatives (RRI) and Public Service Charters Systems.

Performance evaluation/appraisal, a process by which a manager or supervisor evaluates an employee, is widely touted by human resource scholars, professionals, and practitioners. The goal of a performance appraisal is to do more than point out poor, good, or excellent performers. It is also important to understand that a performance appraisal is not used solely for the purposes of discipline or remediation but as part of a continuous improvement process. The many purposes of ongoing performance appraisal process may help an organization to succeed. The goal is to use resources, meaning people, to help drive the organization's mission. 
The biggest challenges faced by counties is developing the capacity to deliver services and track implementation. Performance management is an indispensable requirement for effective county management. Although there are several reasons counties should consider measuring the performance of their programmes and services, the most compelling one is that citizens demand and deserve quality service. The evidence of effective performance management in a county is essentially indicated by improved service delivery. It is fundamentally about driving and monitoring results and the correct behaviours of people (Standard Digital Media, November 2014).

\subsection{Identification of the Problem}

Studies have been done on PM in the defunct Local Authorities in Kenya but very few on the County Governments. Nzuve, (2013) also focused on factors affecting performance management among Local Authorities in Kenya. The study concluded that the perceived factors that influenced performance management were understanding of performance management, stakeholder involvement, continuous monitoring, feedback, dissemination and learning from results, organizational culture and leadership commitment. Gichimu (2010) in a study found out that significant factors influencing the successful implementation of an employee performance management system, to be the users' understanding of the system and creation of a conducive working relationship that fosters performance. Mwangi (2008) investigated the use of rewards as a performance management strategy by insurance companies in Kenya concluded that there is a significant relationship between reward management practices and employee retention.

The importance of performance management system is on continuously improving organizational performance, and this is achieved by improved individual employee performance. Therefore, improving employee performance by using performance management system is away to improve organizational performance.

There are limited studies on Performance Management Systems on the devolved units of government, this study focuses on the existing literature gaps and recommend the intended benefits on PMS thereof. The failure of the top management to support the counties such as, (failure to involve all stakeholders in the development of the PMS, continuous monitoring, feedback, dissemination and learning from results, staffing gaps at the middle level management) to operationalize performance management at the county must be reinforced by the recommendations of the study. We propose a framework to address gaps that has immensely contributed to poor service delivery and the low implementation of developmental projects at the counties. 


\subsection{Justification}

Performance measurement is often taken to be fundamental to delivery of improved services. Emphasis on performance management for delivery of results is undoubtedly influenced by the basic assumption which lies in its professed ability to merge the attention of institution members on a common objective and galvanize them towards the attainment of this objective (Balogun, 2003). Operationalizing a PM in County Governments is therefore important in making sure that Counties demonstrate their development results. Subsequently, it means that PM in County Governments will mark a paradigm shift and a new dimension that Counties will no longer just demonstrate what they have done but rather how their activities and interventions have benefited the people of Kenya.

Out of 47 Counties in Kenya, only 27 Counties have put in place a Performance Management System as shown in table below:

\begin{tabular}{|l|l|l|}
\hline SNo. & Tool & Remarks \\
\hline 1 & $\begin{array}{l}\text { Performance Contracting } \\
\text { Guidelines. }\end{array}$ & $\begin{array}{l}\text { 27 Counties have put in place a Performance } \\
\text { System, Baringo, Bungoma, Busia, Embu, } \\
\text { Homabay, Kakamega, Kericho, Kilifi, Kisii, } \\
\text { Kisumu, Kitui, Laikipia, Lamu, Machakos, } \\
\text { Makueni, Migori, Mombasa, Nairobi, Narok, } \\
\text { Nyandarua, Nyeri, Siaya, Taita Taveta, Tharaka } \\
\text { Nithi, Tranzoia, Vihiga and West Pokot }\end{array}$ \\
\hline 2 & $\begin{array}{l}\text { Guidelines for the } \\
\text { development of County } \\
\text { Integrated Monitoring and } \\
\text { Evaluation System } \\
\text { (CIMES). }\end{array}$ & $\begin{array}{l}\text { Turkana has put in place an M\&E system and } \\
\text { Committees and Kwale County has M\&E policy } \\
\text { County Delivery System }\end{array}$ \\
\hline 3 & \begin{tabular}{l} 
Not yet adopted \\
\hline
\end{tabular}
\end{tabular}

Source: Council of Governors, (COG 2017)

\subsection{Situation Analysis}

The main purpose of the performance management system is to ensure that:

I. The work performed by employees accomplishes the work of the organization;

II. Employees have a clear understanding of the quality and quantity of work expected;

III. Employees receive ongoing information about how effectively they are performing relative to expectations;

IV. Awards and salary increases based on employee performance are distributed accordingly;

V. Opportunities for employee development are identified; and Employee performance that does not meet expectations is addressed 
Macky and Johnson (2000) suggested that a typical performance management system features include: the organization communicates its mission/strategies to its employees; the setting of individual performance targets to meet the employees' individual team and ultimately the organization's mission/strategies; the regular appraisal of these individuals against the agreed set targets; use of the results for identification of development and/or for administrative decisions; and the continual review of the performance management system to ensure it continues to contribute to the organizational performance, ideally through consultation with employees.

Successful organizations are aware that to win in today's competitive marketplace, they must attract, develop and retain talented and productive employees (Varma, Budhwar \& DeNisi, 2008). High performing organizations get their competitive edge from a performance management system that helps them hire talented people, place them in the right position, align their individual performance with organization's vision and strategic objectives, develop their abilities and reward performance commensurate with contributions to the organizations' success.

Counties are facing service delivery issues due to limited capacity and limited resources. The Council of Governors developed a County Performance Management System intended to provide tools to aid the Governors drive forward their manifesto and development agenda (CPMS Handbook, 2016). However, counties have not fully embraced this County Performance Management Framework (CPMS) and the 27 counties that have adopted either one or more tools of the CPMS have cited various challenges. The challenges include: inadequate funds to train the entire workforce on performance contracting and performance appraisals, non-commitment by the top management, staff attitude towards embracing PMS and setting of highly ambitious County Integrated Development Plan (CIDP) not aligned to the Kenya Vision 2030.

The content of CIDP and Annual Development Plan, and quality of performance indicators and targets strategy, are by far the most important elements of an effective performance management system. Performance management is achieved when there are indicators and targets measuring the 
inputs, outputs and outcomes of development projects, as well as financial and non-financial activities.

\begin{tabular}{|c|c|c|}
\hline $\begin{array}{c}\text { INPUTS } \\
\text { (PERFORMANCE) }\end{array}$ & $\begin{array}{c}\text { OUTPUTS } \\
\text { (PRODUCTIVITY) }\end{array}$ & $\begin{array}{c}\text { OUTCOMES } \\
\text { (STATE OF } \\
\text { DEVELOPMENT) }\end{array}$ \\
\hline
\end{tabular}

Source : http://www.blgs.gov.ph/lgpms

The implementation of a PMS is precipitated by: the level of involvement of employees in the designing of the system; the extent to which the system is understood and supported by the managers; extent to which corporate goals are aligned with individual and team goals, how specific, measurable, achievable, realistic and time specific the goals are, extent to which the system enables the supervisors to provide ongoing feedback to spilt and whether

The quality of services is affected not only by the economy, politics and social conditions, but also by performance management practices. An effective system aims at achieving agility for sustainable success and entrenching a performance-driven culture. To be effective, counties should move beyond legislated requirements and adopt a system that directs available resources to what is important, achieves the improvement of service delivery and citizen satisfaction.

Counties that have embraced PMS have adopted mainly the Performance Contracting, Performance Appraisal System, Service Delivery System, Work Plans, and Rapid Results Initiative System.

\subsection{Situational Challenges}

Devolved units (counties) have experienced unprecedented change, and are at the same time faced with many service delivery and development challenges. Development prioritization is critical, and decisions are made based on evidence. Thus, counties are expected to measure absorption of funds and achievement of development results.

Secondly there is no alignment due to various organizational processes being created in isolation. Strategy development, budgeting, operational planning and implementation of the CIDPs and ADPs, departmental strategic plans and the Spatial/Sector Plans are developed by different groups of people with different frameworks adopted hence resulting to non-alignment between individual performance, departmental performance and organizational goals.

Thirdly, some counties have embraced PMS contracts and set ambitious targets that are not achievable. In other cases, no data can be 
collected or is kept as evidence to track performance and inform proper future decision making (GDS, 2016).

Fourthly, counties that have embraced PMS fail to give the due attention and commitment in its development and this affects the successful implementation of the PMS. The commitment and understanding of leadership and management of the requirements for achieving a workable performance system is critical to any performance success (Armstrong, 2001).

Fifthly, a few counties that have embraced PMS, have either failed to cascade performance contracting or failed to conduct and review staff performance appraisals. Management needs to appreciate that performance management is not an event but something that is managed daily but recorded and reported at certain times through reviews and appraisals (Lawler, 2005).

Lastly, political influence poses a great challenge to operationalization of PMS in the counties. Governors have not harmonized the already developed PMS framework to be adopted and embraced across the board.

Unfortunately, measuring the efficacy of a performance management system can be a problematic. The goal of performance management is to maximize organizational performance, but many other factors are likely to influence the success of a company. Just because an organization has a great quarter or year does not mean that its management practices deserve all the credit.

\subsection{Proposed mitigation and intervention strategies}

The success of PMS in the counties must be demand driven as a best practice phenomenon in the development agenda. Governors, CEC Members and Chief Officers must actively spearhead county PMS implementation, including monitoring and evaluating the results thereof. The ADP should include a list of projects and their budgets, preferably as a programme-based budget in alignment to the CIDP, departmental strategic plans and the Spatial/Sectoral Plans.

Capacity building of human capital on PM at all levels of management through identification and prioritization needs and implementation of the county vision. Improvement on service delivery, achievement of results, and demonstration of progress to citizens, the county must have the ability to monitor, evaluate and act on the results achieved - based on timely evidence. Consequently, it is important for a county to produce timely and accurate information across all systems leading to faster and better decisions.

The county PMS needs leadership and commitment from the Governors and the executive team. This executive team will ensure each officer using the PMS system is accountable and responsible for providing information and data. The county CEO (Governor) is essential to the success of the Performance Management System. The commitment and follow up, 
driving accountability and service delivery, using the county PMS can significantly accelerate the speed of development and the quality of service delivery in the county (GDS, 2016)

To improve performance management in counties, individual accountability is critical, where performance is assigned and measured within a defined period. Counties should therefore focus on performance improvement both at the strategic and operational levels to unlock the full potential of the available resources and infrastructure through cascading the PC from the top management to the middle management and conducting Staff Performance Appraisals for all other staff. Proper evaluation and assessment mechanisms should also be put in place.

The Council of Governors in conjunction with the Ministry of Devolution and Planning should put in place a policy framework on performance management aligning both the NPMF and the CPMF. This will therefore discourage unnecessary political interference.

Finally, to achieve sustainable success, counties should take advantage of change (whether planned or unexpected) with the aim of owning the process and giving it due attention. It will require the ability to move quickly, adapt to change and address it smartly, while simultaneously keeping the county on course.

In summary, counties should align individual and company goals, reward performance, identify poor performers, leverage technology and avoid legal battles.

\subsection{Implications of the performance management on Counties}

Performance management is a continuous process that creates a working culture that encourages employees to improve their work performance and reach their full potential during their stay of employment. Secondly, Performance Management also provides strategic direction, develop competency in employees and instill organization value.

According to Gagne (2002), if individual employees know what their priorities are, they will follow those priorities. Performance management gives managers and employees more say in setting their goals and more accountability for accomplishing them. Consequently, this implies that performance management does not necessarily fix problems but eliminates challenges that causes the problems.

The PMS will increase visibility and make County Governments accountable and transparent. In Taita Taveta County, the PMS is a tool that will make them hold themselves accountable to the people of county, and will transform all the institutions within the county through this system (CPM, Handbook, 2016). The Laikipia County Governor asserted that "As a county, how can we hold ourselves accountable to the people? What have we been 
doing? We do a lot as a county, but we have not communicated enough to our people. This is the best time for us as a county to make proper use of the system and ensure we have visibility, transparency and accountability." The system will also ensure quality delivery of services, enhance Human Resource Management and coordination of public service performance. This was confirmed by a team of County Chief of staffs (September 2014) in a workshop on County Performance Management System (CPM, Handbook, 2016).

With the PMS in place in the counties, there will be needing to measure and show value for money expended in development and to get updates on the progress being made on a timely basis. This is because targets are set with a timeframe in mind and tasks must be completed within the timeframe.

The purpose of implementing the County PMS is to ensure that performance happens by design and not by chance. Thus, the PMS ensures the linkage between planning, budgeting, accountability and results, in the counties. Thus, by ensuring accountable delivery of priority and flagship projects in areas such as in infrastructure, agriculture, health, climate change and resilience, the county PMS provides a mechanism through which the political and administrative leadership of the county can improve the lives of Kenyans.

PMS in counties will ensure that the most important services and projects get initiated, and delivered. Without priority and focus, resources may be misallocated, and key projects will not get the focus as planned. For this reason, it is important that each County Executive Committee Member and County Chief Officer agrees the priority projects and services for each ministry (department).

Finally, the PMS will provide the county leadership and officers with a finger on the pulse of development results, including who is accountable for each project and service, together with the evidence recorded and the results produced.

\subsection{Conclusion}

County Governments have a constitutional responsibility to engage with, listen to and account to their citizens about use of public funds. Comparison of the use of these funds for the analysis of public service performance is the only way of justifying the use, other than bureaucracy. Kervasdoue (2007) asserts that, there is no disagreement that performance evaluation is necessary in public affairs. Governments and their bureaucrats must be accountable to their citizens about the use of taxes and public funds.

Upon the adoption of PMS framework, counties shall promote accountability in service delivery at the County level by ensuring that tasks are performed efficiently, effectively and economically. It also provides a 
mechanism for Citizens to engage and evaluate the performance of their county governments.

Finally, adopting a reliable performance management system is not negotiable for county governments if they are to deliver on their core mandate, achieve their objectives and improve service delivery.

PMS is one of the managerial techniques that improve the performance, attain and sustain competitive advantage of an organization. Subsequently, the implementation rate of PMS is high in the contemporary organizational environment as a best practice. Hence, the organization should put their greatest effort for successful implementation of PMS either through financial resource or human resources.

\subsection{Recommendations}

The government of Kenya in a milestone contained in the 2010 Constitution, has addressed the question of leadership, governance and management of public resources. This is documented in Mwongozo Code of Governance for State Corporations (MCoGSC, 2015). Mwongozo allocates responsibilities for supervision, implementation and enforcement while recognizing the role of complimentary agencies. This framework is envisaged to lead a positive impact of the national budget while improving the public's perception for quality and delivery of public service. The following raft of recommendations if implemented will address PMS issues:

a) Execute a performance management system that is linked to the mandate of the organization and which is aligned to the national development plans and sector performance standards to reflect the corporate culture and values.

b) Set realistic performance targets that will form the basis of performance evaluation and focus on the right company performance measures.

c) Ensure that the performance targets are measurable and link compensation to PMS - merit increases, short/long-term and discretionary incentives.

d) Agree on the performance parameters and targets with the National Government or oversight body and ensure that the obligations of the parties are documented. Require managers to actively search out, offer and acquire performance feedback on a regular basis.

e) Ensure that the performance targets are cascaded to the management and staff of the organization through a performance management system and communicate the total reward system.

f) Continually monitor organizational performance and identify areas that require improvement. Capacity build managers in performance management. 
g) PMS is premised on a foundation that include; the first building block is a focus on outcomes-performance of the public services which should be assessed based on results. The second one involves devolving responsibility for the delivery of services to employees, subject to appropriate minimum standards and regular performance monitoring. The final building block is about improving the governance of public services, by reforming institutions to reflect the importance of clear objectives, appropriate incentives and good performance information in the achievement of higher productivity.

\section{References}

Armstrong, M. (2000). Performance Management. Key Strategies and Practical Guidelines. London: Kogan Page Limited.

Armstrong, M., \& Baron, A. (1998). Perfomance Management: the new realities. London: Institute of Personel and Development.

Balogun, J., Huff, A. S., \& Johnson, G. (2003). Three responses to the methodological challenges of studying strategizing. Journal of Management Studies, 40(1), 197-224.

Buchner, T. W. (2007). Performace Management Theory: A look from the performer's perspective with implications for HRD. Human Resource Development International, 10(1), 59-73.

Council of Governors of Kenya. (2016). County Performance Management System and Stakeholder Engagement Handbook. Nairobi: Government Press. Council of Governors of Kenya. (2017). Performance Management Framework for County Governments. Nairobi: Government Press

Gagne, K. (2002, January 30). Using performance management to support an organization's strategic business plan Volume 28, Issue 4. Wiley Periodicals Inc, pp. 53-59.

Gichimu H. A. (2010) Factors influencing successful implementation of employee performance management systems at KPMG

Government of Kenya. (2007). Economic Recovery Strategy for Wealth and Employment creation (2003-20087. Nairobi: Government Press.

Government of Kenya. (2012). The Public Finance Management Act. Nairobi, Kenya: Government Press.

Hartle, F. (1995). How to Re-engineer your Performance Management Process. London: Kogan Page.

Hope, K. R. (2001). The New Public Management: Context and Practice in Africa, International Public Management Journal, Vol. 4 No. 2

Kervasdoue, J. (2007) Rating and Evaluating Health Systems: Reinforcing the Partisan Spirit or Investigating the Public Good? Paper prepared for the IPMN 
Workshop, 'Ranking and Rating Public Services', Worcester College, Oxford, 7-9 August 2007

Lawler III, E. E. (2005). Creating high performance organizations. Asia Pacififc Journal of Human Resources Volume 43. Issue 1, 1-15.

Macky, K., \& Johnson, G. (2000). The strategic Management of Human Resources in New Zealand. Auckland, New Zealand: Irwin/McGraw-Hill Mwangi (2008) The use of rewards as a performance management strategy by insurance companies in Kenya

National Council for Law. (2016). COUNTY GOVERNMENTS ACT. NO. 17 OF 2012.

Nzuve, S. M., \& Njeru, L. K. (2013). Perceived factors affecting Performance Management among Local Authorities in Kenya: A Case of the City Council of Nairobi. Africa Management Review August, Vol 3 No.2, 59-69.

Public Service Commission (2015). Mwongozo Code of Governance for State Corporations. Nairobi: Government Press.

The Standard Digital Media (3rd November 2014). Performance management key to making devolution a success. Accessed on 5/10/2017

Therkildsen, O. (2001). Efficiency, Accountability and Implementation: Public Sector Reform in East and Southern Africa. UNRISD Program Paper No. 3, (pp. 16-131). Geneva.

Tse, J. (2007). The Changing Phase of Performance Management Systems. People Management Vol. 13 No. 2, 35-36.

Varma, A., Budhwar, P. S., \& Denisi, A. S. (2008). Performance Managment Systems: A Global Perspective. Abingdon: Oxon. 